\title{
Do livro literário clássico às narrativas de arte sequencial: uma proposta metodológica experimental utilizando-se a obra A Terra dos Meninos Pelados como objeto de estudo

\author{
From classic literary book to the narratives of sequential art: an experimental \\ methodological proposal using the work A Terra dos Meninos Pelados as object of \\ study
}

Beatriz Montenegro, Mariana Hennes

design editorial, arte sequencial, Graciliano Ramos, concept art

\begin{abstract}
As adaptações de livros literários tradicionais para linguagem de arte sequencial vêm ganhando destaque no cenário educacional brasileiro por se caracterizar como uma alternativa com alto poder de engajamento junto ao Programa Nacional Biblioteca na Escola (PNBE) do Governo Federal. Assim, o presente trabalho tem o objetivo de apresentar uma proposta de metodologia elaborada para esse fim, utilizando-se o clássico literário A Terra dos Meninos Pelados, de Graciliano Ramos, como objeto de estudo. Para tanto, os materiais, métodos e ferramentas de design aplicadas pretenderam atender tanto as necessidades identificadas no processo de criação do concept art do livro (a partir do levantamento e análise de dados referentes à obra supracitada), quanto o processo de desenvolvimento do projeto gráfico e produção editorial do artefato. Deste modo, o trabalho foi dividido em duas fases distintas que foram executadas, em algumas etapas, simultaneamente. Após percorrer um caminho de onze etapas metodológicas, definidas com finalidades específicas, chegou-se a uma solução editorial adequada ao público infanto-juvenil, que atendeu às necessidades e restrições de projeto, identificadas para a adaptação literária.
\end{abstract}

editorial design, sequential art, Graciliano Ramos, concept art

The adaptations of traditional literary books to sequential art language have been gaining prominence in the Brazilian educational scenario because it is characterized as an alternative with a high power of engagement along with the National Library's School Program (PNBE) of the Federal Government. Thus, the present work aims to present a methodology proposed for this purpose, using the literary classic $A$ Terra dos Meninos Pelados, by Graciliano Ramos, as object of study. In order to do so, the applied materials, methods and tools of design intended to meet both the needs identified in the process of creating the concept art of the book (based on the collection and analysis of data referring to the aforementioned work) and the process of development of graphic design and editorial production of the artefact. Thus, the work was divided into two distinct phases that were performed, in some steps, simultaneously. After following a path of eleven methodological steps, defined for specific purposes, a suitable editorial solution was reached for children and youth audience, which met the needs and design restrictions identified for the literary adaptation.

\section{Introdução}

Os veículos da narrativa em arte sequencial como revistas de quadrinhos, graphic novels e seus derivados, se utilizam da sobreposição de elementos verbais, pictóricos e esquemáticos da linguagem gráfica (LG) como ferramenta narrativa e apresentam atributos que auxiliam no desenvolvimento cognitivo do leitor. Embora se caracterizem por ter, nos elementos pictóricos (ilustrações), a maior carga informacional dos conteúdos, esses produtos gráficos são considerados artefatos formadores de valores, conhecimento e opiniões, assim como qualquer livro literário tradicional.

O reconhecimento desse gênero como um importante instrumento educativo pode ser comprovado pela sua adoção em programas de incentivo à leitura, como o Programa Nacional Biblioteca na Escola (PNBE) do Governo Federal brasileiro, que tem o intuito de estimular a formação de leitores dentro e fora de ambientes escolares. Das histórias em quadrinhos presentes nas listas de livros do PNBE, encontram-se adaptações da literatura clássica para

Anais do 8CIDI e 8CONGIC

Guilherme Santa Rosa; Cristina Portugal (orgs.)

Sociedade Brasileira de Design da Informação - SBDI

Natal | Brasil |2017

ISBN 978-85-212-1305-5
Proceedings of the $8^{\text {th }} \mathrm{CIDI}$ and $8^{\text {th }}$ CONGIC

Guilherme Santa Rosa; Cristina Portugal (orgs.)

Sociedade Brasileira de Design da Informação - SBDI

Natal| Brazil |2017

ISBN 978-85-212-1305-5 
graphic novels, como O Alienista, de Machado de Assis; O Guarani, de José de Alencar; Dom Quixote, de Miguel de Cervantes; entre mais de 20 títulos. Alguns autores, como Yamaguti (2014), defendem que essas adaptações podem funcionar como propostas de incentivo à leitura, pois quando um jovem sem o hábito de ler engaja-se a uma graphic novel tem maiores chances de se interessar também pela obra original. Além disso, trata-se de uma alternativa para a ampliação do repertório cultural/literário dos jovens em idade escolar, já que as histórias em quadrinhos geralmente exercem um poder de envolvimento sobre o público infanto-juvenil maior que os livros clássicos de literatura tradicional.

No entanto, apesar da crescente adoção de livros de arte sequencial nas atividades didáticas de escolas brasileiras, verificou-se que, no estado de Alagoas, terra natal de grandes mestres da literatura nacional, pouco se tem feito em relação à renovação dos projetos gráficos de obras literárias clássicas, para formatos e linguagens mais acessíveis à população local.

Dentre as personalidades alagoanas de maior destaque cultural está o escritor alagoano Graciliano Ramos, que recebeu o prêmio de Literatura Infantil do Ministério da Educação no ano de 1937 com a obra A Terra dos Meninos Pelados. O livro, apesar de escrito há quase oito décadas, ainda pode ser considerado bastante atual por trazer, como tema central, a problemática da discriminação - a qual é abordada sob a ótica das diversidades físicas, sociais e culturais das pessoas. Com uma linguagem simples, Graciliano deixa como principal reflexão as razões pelas quais se devem abraçar as diferenças, antes motivos de exclusão, para a construção de um mundo mais humano.

Apesar do conteúdo literário de grande valor presente em A Terra dos Meninos Pelados, percebe-se que os recursos gráficos de edições anteriores dessa obra foram pouco explorados, como formatos do livro, estilos tipográficos para títulos e corpo do texto, paletas de cores, estilos de traço das ilustrações e a escolha dos materiais e processos de produção gráfica. Isso se deve, principalmente, ao fato de o mercado editorial no Brasil, voltado a atender o público infanto-juvenil, ainda ser considerado recente, especialmente na região Nordeste. Portanto, até meados da década de noventa, os recursos voltados à área de produção de livros, como materiais e processos de produção e impressão, eram limitados, além do fato de designers gráficos não participarem ativamente de todas as etapas de desenvolvimento do livro aspecto, hoje, considerado imprescindível (Romani, 2011).

Neste sentido, a intenção do presente trabalho é apresentar uma proposta metodológica híbrida que facilite o processo de adaptação de livros literários tradicionais para livros que se utilizam da linguagem de arte sequencial como narrativa. Elegendo-se a obra A Terra dos Meninos Pelados como objeto de estudo, é possível considerar que os materiais, métodos e ferramentas adotadas obtiveram êxito nessa perspectiva, por atender tanto o processo de criação do concept art do livro a partir do levantamento e análise de dados referentes à obra supracitada, quanto o processo de desenvolvimento do projeto gráfico e produção editorial do artefato. Assim, a solução final gerada pode ser considerada inovadora na medida em que se diferencia das edições anteriores, por meio da integração dos valores literários apresentados em A Terra dos Meninos Pelados aos princípios do design editorial e à linguagem em arte sequencial no formato de graphic novel.

\section{0 design editorial e as narrativas em arte sequencial}

Área de conhecimento atrelada ao design gráfico, o campo do design editorial envolve todas as ferramentas e processos considerados primordiais para qualquer tipo de publicação. No caso dos livros, o formato e os estilos dos elementos gráficos, bem como os materiais, acabamentos e outros recursos, são fatores determinantes para despertar o interesse do leitor e manter seu engajamento durante a leitura. Para Lins (2003), quando se trata de livros literários infantis, os valores estético-formais são ainda mais relevantes, e devem ser trabalhados de forma que o conteúdo seja assimilado de maneira eficiente e prazerosa, sem desconsiderar que, por mais divertido que seja, o livro literário é um objeto de leitura e não um brinquedo.

Na visão de Farbiarz \& Farbiarz (2010), é função do designer interpretar e articular todos os aspectos verbais e visuais contidos no livro, para que, dessa forma, o projeto editorial não apenas facilite a leitura, mas também contribua com a formação do senso crítico do leitor. Para isso, o designer precisa enxergar o seu projeto com os olhos do público para o qual o produto final será direcionado. Nesse sentido, Farbiarz \& Farbiarz (2010) aludem que 


\section{CIDI 2017}

O designer pode gerenciar a linguagem visual utilizada na elaboração de livros para facilitar o processo perceptivo, minimizando obstáculos que dificultam a leitura e a compreensão. Se o designer, durante o projeto, tiver conhecimento dos mecanismos de construção de significados desses elementos, o receptor compreenderá melhor seu conteúdo verbal e não verbal (Farbiarz \& Farbiarz, 2010: 149).

De acordo com Fonseca (2008), todas as decisões tomadas no desenvolvimento de um projeto editorial devem corresponder às necessidades e expectativas dos usuários finais, bem como a finalidade de sua publicação. Em se tratando do projeto aqui descrito, apesar da obra $A$ Terra dos Meninos Pelados ser, geralmente, direcionada ao público infantil - já que as edições literárias existentes adotaram atributos gráficos mais condizentes com esse perfil -, uma das diretrizes definidas para a presente proposta foi a de desenvolver um projeto capaz de dialogar com outros perfis de leitores. Assim, estabeleceu-se que o livro deveria dialogar com indivíduos de faixas etárias diferentes, desde que nutrissem o interesse pelo gênero de arte sequencial, pelas referências culturais da literatura alagoana e/ou pelo legado de Graciliano Ramos.

Para alcançar esse fim, decidiu-se explorar um gênero que se utiliza da integração dos elementos da linguagem gráfica (LG) de caráter verbal, esquemático e pictórico para construção das narrativas - sendo a esse último (caráter pictórico) atribuído um peso quantitativamente maior.

As histórias em quadrinhos, de acordo com McCloud (1995: 9), 'são imagens pictóricas e outras justapostas em sequência deliberada, destinadas a transmitir informações e/ou a produzir uma resposta no espectador'. Pode-se dizer, então, que histórias em quadrinhos são formas de expressão artística que incorporam textos, imagens e outros elementos com o intuito de narrar uma história fictícia, um evento real, ou um momento dentro de qualquer período temporal ou imaginativo.

Um dos pontos positivos sobre narrativas em sequência é a forma como elas conseguem interagir com leitores de qualquer faixa etária. Sobre esse aspecto, pode-se ressaltar que, dentre a gama infinita dos assuntos que podem ser abordados nas histórias em quadrinhos, é possível encontrar de temas infanto-juvenis, como os quadrinhos da Marvel e da DC Comics, cujas histórias envolvem o aventuresco universo dos super-heróis, a temas de caráter mais adulto, abordando a sociedade e seus valores pessoais, morais, políticos, ideológicos, sexuais etc. Por isso, é de extrema importância que a história em quadrinhos, independentemente do formato no qual se apresente, seja reconhecida como um importante artefato na formação crítica e autônoma dos leitores enquanto indivíduos detentores de valores morais e éticos.

$\mathrm{Na}$ última década, esse tipo de artefato gráfico editorial - que traz o formato da arte sequencial para uma narrativa literária - foi dividido e classificado em diversas categorias pelos profissionais atuantes na área. Dentre elas, destaca-se o grupo das graphic novels, ou, na tradução para a língua portuguesa, romances gráficos. Embora não exista, ao certo, nenhum requisito que diferencie as graphic novels das histórias em quadrinhos, alguns autores separam esses dois termos de acordo com certos elementos gráficos e literários presentes nas duas narrativas, além de características do autor e do lugar de publicação.

Para o especialista em HQs - histórias em quadrinhos - Andreas Platthaus (Platthaus, 2011), o romance gráfico não precisa ser contado no formato clássico das revistas ou álbuns, e o número de páginas contido em um exemplar pode variar, assim como ocorre nos romances literários - justificando a adoção do termo novel para designar esse tipo de narrativa gráfica. Normalmente, a graphic novel não é produzida no formato de série (como acontece com as histórias em quadrinhos, que costumam ser publicadas em edições periódicas), sendo uma de suas características a existência de começo, meio e fim em um único volume, como um romance literário tradicional.

Em termos de conteúdo, há autores que caracterizam estes romances gráficos como livros voltados ao público adulto, por abordarem, em sua maioria, temas mais profundos além exigirem uma leitura (verbal e visual) mais densa e complexa. Embora essa ocorrência seja comum, concordamos com Platthaus (2011), quando defende que não há nenhuma regra, em relação ao conteúdo da história, que separe uma graphic novel de uma $\mathrm{HQ}$, existindo histórias em quadrinhos que também podem sem classificadas como adultas, devido à temática abordada e/ou linguagem utilizada.

Assim, definindo-se nosso projeto como uma graphic novel, passível de ser desenvolvida segundo processos ligados tanto ao design editorial de livros quanto a criação de histórias em 
quadrinhos, buscou-se na literatura disponível uma metodologia que se adequasse às necessidades identificadas.

Nesse sentido, foram analisados dois trabalhos similares que também se propuseram a desenvolver soluções para problemas de design editorial. Para isso, fizeram uso de metodologias atreladas a áreas afins, adaptando-as para seus projetos de design editorial. Essas duas adaptações, propostas por Selbach (2010) e Festenseifer (2012), foram necessárias devido ao fato de não haver, nas bibliografias relacionadas, alternativas metodológicas de projetos editoriais que atendessem às especificidades dos seus trabalhos. Entende-se, com base nessa constatação, que é possível chegar a um processo metodológico ideal a partir da fusão de metodologias de diferentes campos do design.

Assim, Festenseifer (2012: 14), ao realizar um trabalho voltado à área de design editorial de livros infantis, combinou as metodologias de Ambrose \& Harris (2011) e Munari (2008) para a geração de sua própria proposta, a qual contou com cinco etapas distintas: conceituação, estudos e definições formais, projeto gráfico, modelo e resultado final. Já Selbach (2010: 87), em seu estudo de adaptação literária para histórias em quadrinhos, utilizou o conto A Cor Que Veio do Espaço, de H. P. Lovecraft como objeto de estudo. Em seu trabalho, adotou a metodologia desenvolvida para projetos de sistemas de identidade visual proposta por Peón (2000) como base para sua proposta, realizando interessantes adaptações. As etapas seguiram uma sequência lógica, e foram descritas como: delimitação do projeto, análise de similares, análise de público-alvo, conceituação, geração de alternativas, escolha da alternativa, definição da solução final, detalhamento técnico e model sheets.

O fato do trabalho aqui proposto levar em consideração dois aspectos importantes do projeto gráfico editorial, a saber: (a) a adaptação da obra literária para o formato de arte sequencial, com geração dos concept arts e ilustrações; e (b) o desenvolvimento do artefato final em si, com diagramação e projeto gráfico do livro; levou-nos a elaborar uma metodologia projetual que separasse os processos em módulos distintos. A partir da análise das etapas citadas anteriormente, chegou-se a uma proposta experimental adaptada, composta por duas fases. A fase 01, direcionada ao projeto de ilustração, foi dividida em cinco etapas; e a fase 02 , direcionada ao projeto editorial, configura-se em seis etapas. Embora as fases contemplem objetivos diferentes do projeto, algumas etapas de fases diferentes ocorrem simultaneamente em momentos específicos, conforme detalhamento a seguir.

\section{Metodologia de projeto combinada}

Conforme mencionado anteriormente, a fim de tornar o desenvolvimento do projeto mais eficiente, a metodologia proposta foi dividida em duas fases, com cinco e seis etapas distintas, respectivamente (figura 1). A primeira fase contemplou o projeto de ilustração da história em quadrinhos, e baseou-se na metodologia proposta por Selbach (2010). A segunda fase, referente ao projeto editorial, fundamentou-se na metodologia de Festenseifer (2012), que engloba a diagramação e a produção da graphic novel. As fases e etapas foram descritas a seguir. 


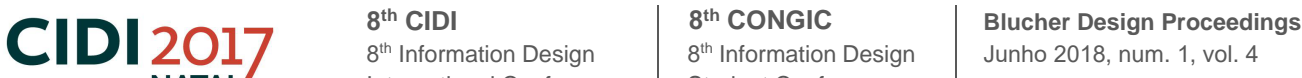

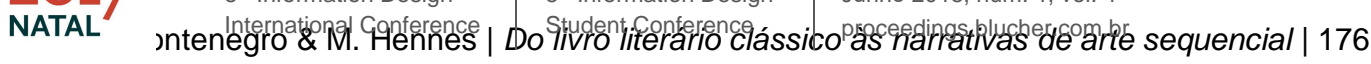

Figura 1: Esquema metodológico dividido em duas fases distintas.

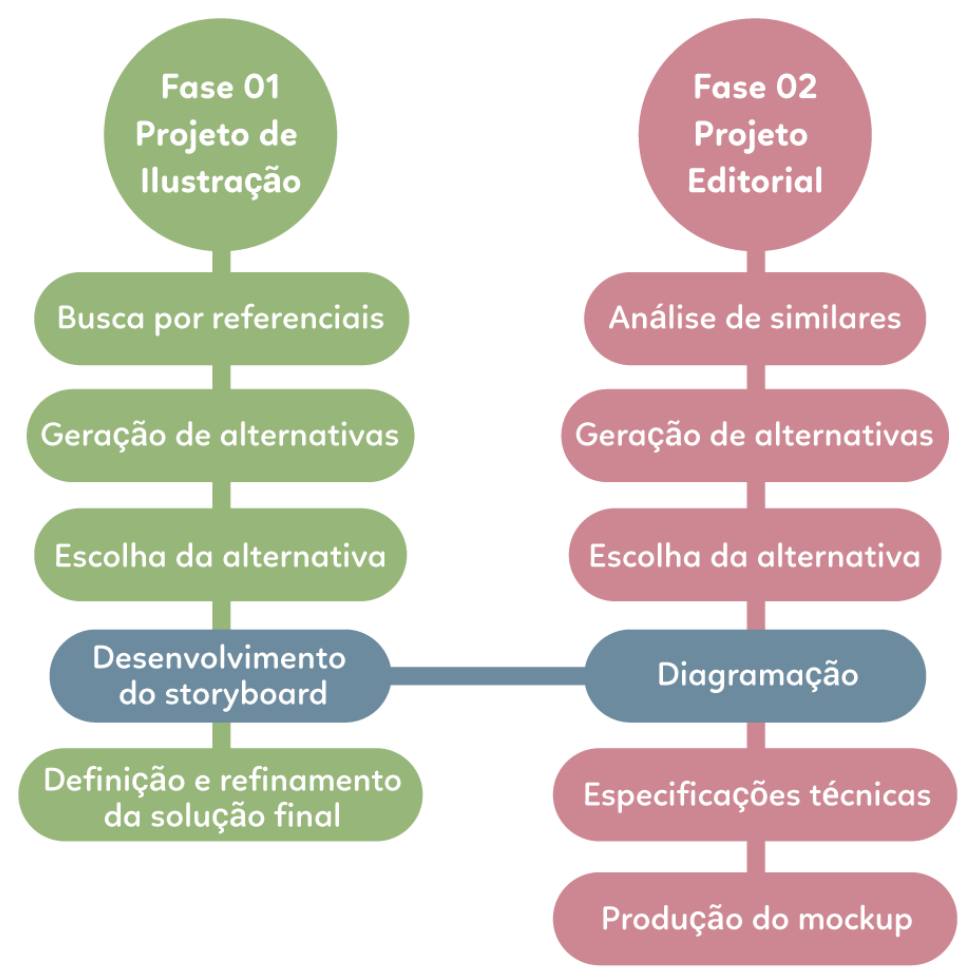

Desse modo, a fase 01 da metodologia, referente ao projeto de ilustração, iniciou-se com a busca de referenciais para o desenvolvimento das ilustrações. Posteriormente, deu-se início à etapa de geração de alternativas, na qual ocorreu a elaboração de estudos de personagens e cenários da história, baseados nos pré-requisitos e conceitos determinados. Depois, foi realizada a triagem desse material e, a partir de um estudo mais seletivo, foram escolhidas as alternativas que melhor se adequaram ao projeto. A quarta etapa foi dedicada ao desenvolvimento do storyboard, com aplicação do roteiro e sketches iniciais, realizando-a simultaneamente à etapa de diagramação da fase 02 , dando rumo à narrativa sequencial. $\mathrm{Na}$ última etapa, houve a definição e refinamento da solução, com realização do processo de composição e aperfeiçoamento da proposta final do produto da fase 01 , a partir da aplicação de cor e definição de traço.

Já a fase 02 da metodologia, ligada ao projeto editorial, teve com etapa inicial a análise gráfica de projetos editoriais similares, a fim de encontrar referências relevantes e interessantes para o projeto a ser desenvolvido. Depois, algumas alternativas foram geradas, considerando a escolha dos materiais e processos gráficos aplicados à graphic novel. Em seguida, esse material passou por uma triagem na qual foram escolhidas as alternativas que melhor se adequaram ao projeto. A etapa de diagramação foi o quarto passo da fase 02 e aconteceu simultaneamente à etapa de desenvolvimento do storyboard da fase 01. Assim, foi desenvolvida a diagramação e arte finalização da graphic novel. Na quinta etapa ocorreu o detalhamento técnico e especificações da graphic novel (formato do livro, tipo de capa, tipo de papel para o miolo, cores, processo de impressão, acabamento e tipo de encadernação). A sexta e última etapa foi dedicada à produção do mockup, com a impressão de 10 exemplares, simulando o produto final com o máximo de fidelidade possível.

Embora todas as etapas da metodologia tenham desempenhado uma função essencial para a elaboração da solução final do problema de design identificado, algumas etapas destacam-se por influenciarem, de forma clara e objetiva, as decisões projetuais estabelecidas. Tais etapas serão descritas no tópico a seguir, no qual apresentaremos e discutiremos os resultados obtidos conforme suas aplicações no projeto. 


\section{\begin{tabular}{ll|l|l|l} 
CDI & 2017 & $\begin{array}{l}8^{\text {th }} \text { CIDI } \\
8_{\text {th }}^{\text {th }} \text { Information Design }\end{array}$ & $\begin{array}{l}\text { Blucher Design Proceeding } \\
8^{\text {th }} \text { Information Design }\end{array}$ \\
Junho 2018, num. 1, vol. 4
\end{tabular}

\section{Desenvolvimento do projeto de ilustração e projeto editorial}

A fim de tornar a apresentação e discussão dos resultados desse trabalho mais didática, estes serão apresentados detalhadamente, de acordo com as principais etapas metodológicas que fizeram parte do processo do projeto de ilustração e do projeto editorial da graphic novel à qual se refere este trabalho. Todos os dados obtidos foram gerados a partir da aplicação de métodos e ferramentas de design, ressaltando, além das dificuldades encontradas no percurso, os erros e acertos cometidos até chegar ao produto final.

\section{Projeto de llustração}

\section{Busca por referenciais}

Foram estudados alguns concept artists de animações 3D infantis, como Eric Guillon, que atuou no desenvolvimento de concept art de personagens e cenários em The Lorax, Despicable Me, Despicable Me 2 e Minions. Também foi analisado o trabalho de Dan Krall, responsável pela concept art da animação em stop motion The Boxtrolls, além de outros artistas, como Oliver Jeffers, ilustrador de diversos títulos infantis.

Ao analisar os personagens de Eric Guillon e Dan Krall, percebe-se que, embora estes enquadrem-se na classificação de ilustração icônica, possuem grande riqueza de detalhes, originando características bastante singulares, próprias dos filmes de animação 3D produzidos na atualidade, geralmente com classificação indicativa livre. Já o ilustrador Oliver Jeffers não se preocupa em manter um alto grau de detalhamento, montando personagens e cenários mais simples.

\section{Geração de alternativas}

A etapa foi dividida em dois momentos: o primeiro, composto pela geração de alternativas do personagem central da história; e o segundo, pela geração de alternativas de coloração. Assim, inicialmente, foram feitos esboços do protagonista (figura 2), Raimundo, para somente depois de escolhida a alternativa de traços e coloração, desenhar esboços dos personagens coadjuvantes e dos cenários. Essa ordem de criação se deu pela facilidade em desenhar os personagens com base na estrutura corporal de um único modelo, já que, na história, Graciliano Ramos descreve os meninos pelados como tendo características físicas semelhantes.

Figura 2: Esboços iniciais do protagonista.
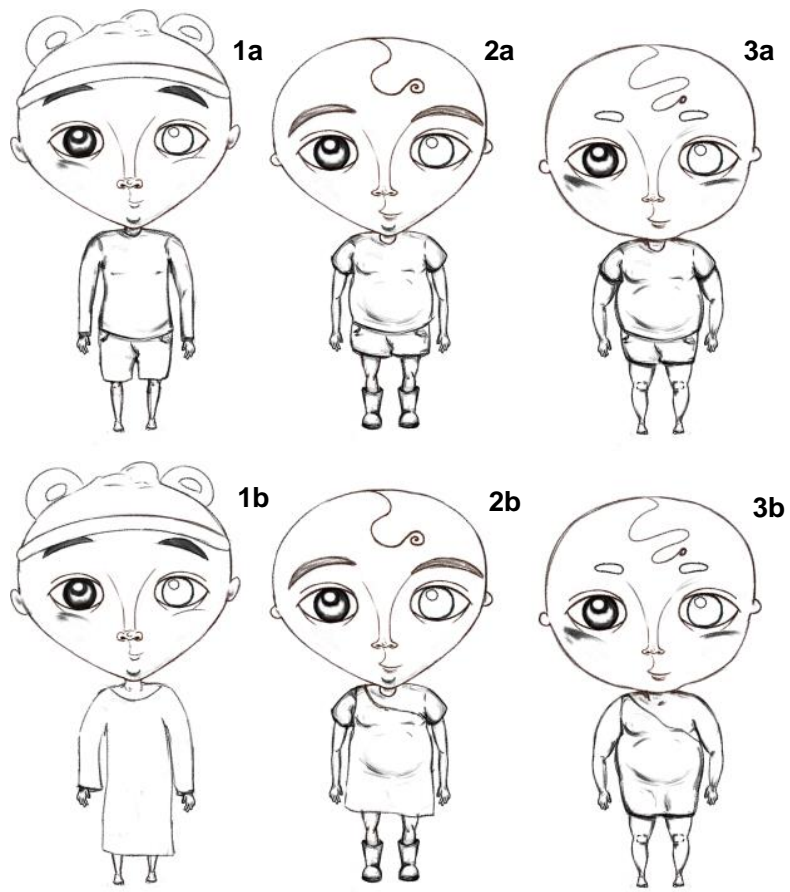


\section{CIDI 2017

Sobre o método de coloração dos personagens (figura 3), nas fases iniciais do projeto de ilustração, considerou-se utilizar um perfil de coloração mais simples (colunas A e B), com cores chapadas, sem dar volume ao desenho. Um dos fatores que poderia ter influenciado na escolha de coloração das opções A e B seria a otimização do tempo: enquanto levou-se, em média, de 15-20 minutos para as colorações $A$ e $B$, de um único personagem, levou-se de 4060 minutos para a finalização da coloração $C$. Contudo, depois da análise de similares e considerando a possibilidade de evolução do livro para um filme de animação 3D, decidiu-se, após alguns testes comparativos, optar pela opção mais complexa (coluna C), atribuindo sombras e volume aos personagens.

Figura 3: Alternativas de coloração.

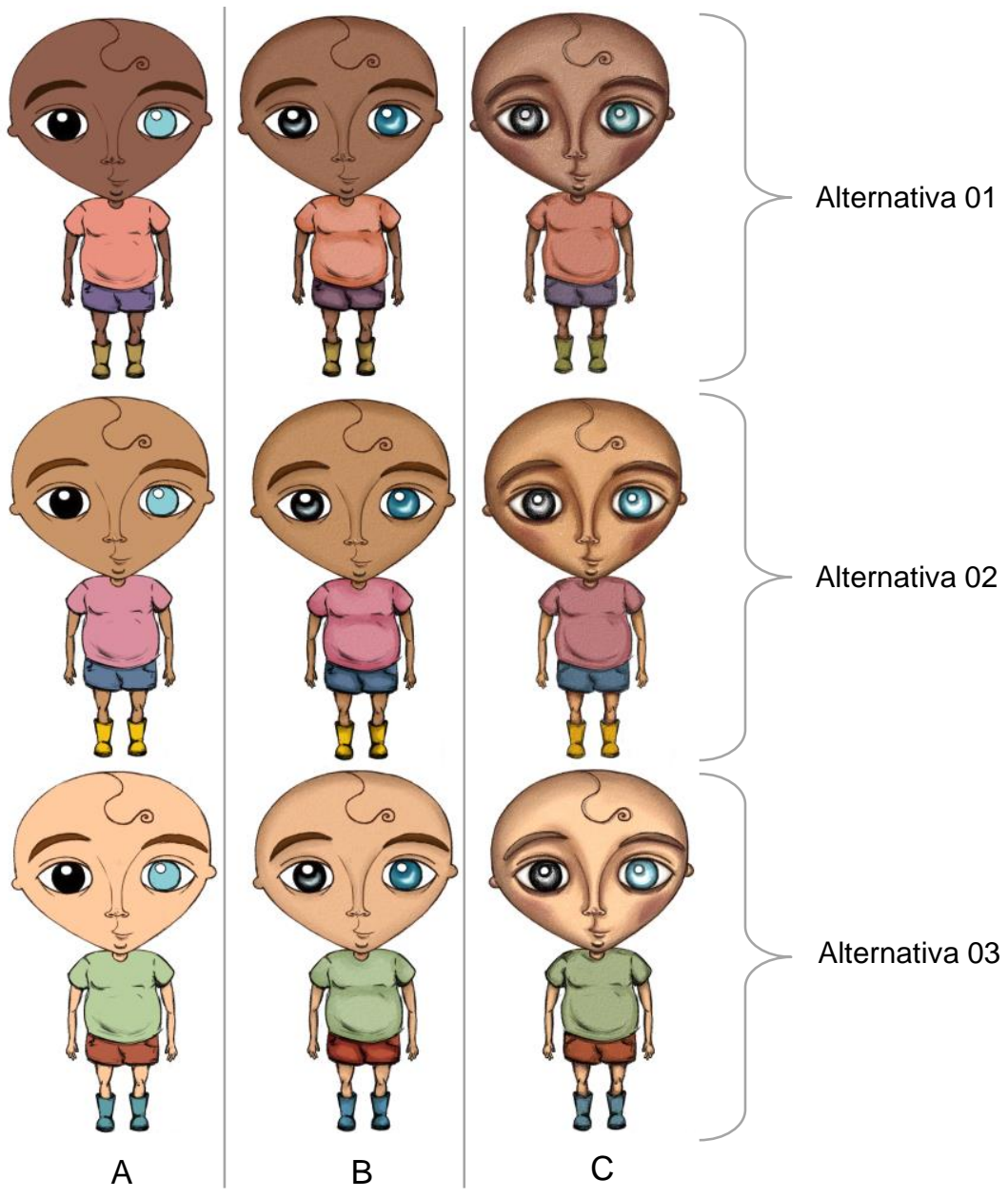

\section{Escolha da alternativa}

Nessa etapa foi realizada uma análise do material gerado na fase anterior e, a partir de um estudo comparativo baseado em critérios relevantes para o projeto, com valores que podiam ser atribuídos entre um e cinco pontos, foi escolhida a alternativa que melhor se adequou à proposta, como é visto na tabela 1.

Tabela 1: Estudo comparativo para escolha da alternativa.

\begin{tabular}{l|l|l|l|l} 
Alternativa & $\begin{array}{l}\text { Corresp. à } \\
\text { descrição } \\
\text { original do } \\
\text { personagem }\end{array}$ & $\begin{array}{l}\text { Aparência } \\
\text { adequada à } \\
\text { faixa etária } \\
\text { do person. }\end{array}$ & $\begin{array}{l}\text { Similaridade } \\
\text { com o perfil da } \\
\text { criança do } \\
\text { interior do NE }\end{array}$ & Total \\
\hline 1 & 5 & 4 & 3 & 12 \\
\hline 2 & 5 & 5 & 5 & 15 \\
\hline 3 & 5 & 3 & 3 & 11 \\
\hline
\end{tabular}




\section{CIDI $2017 \quad 8^{\text {th }} \mathrm{CID}$

Depois do resultado do estudo comparativo, o qual resultou na seleção da opção 2 do desenho do personagem principal, foi executado o refinamento dessa alternativa e o desenvolvimento de todos os personagens secundários, criados com base nas proporções do protagonista (figura 4).

Figura 4: Concept art dos personagens Raimundo (principal), Sardento e Caralâmpia (secundários), respectivamente.
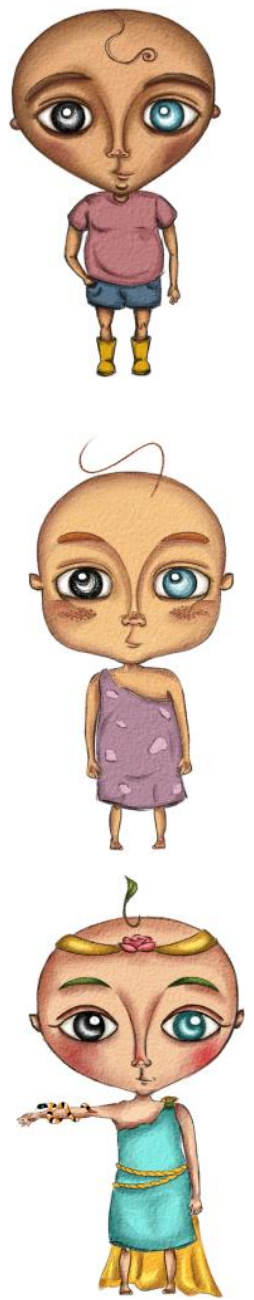
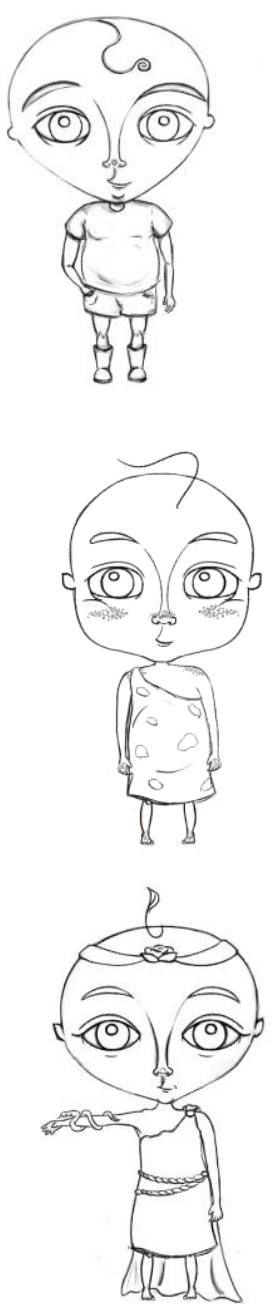
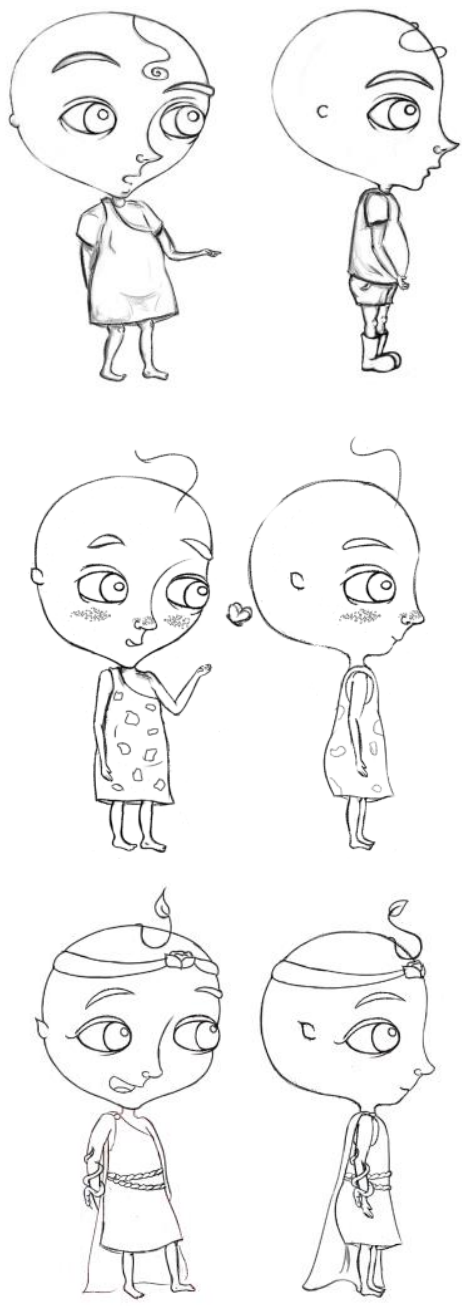

\section{Desenvolvimento do storyboard}

Para o desenvolvimento do storyboard, que ocorreu simultaneamente à etapa de diagramação do projeto editorial, foi necessário estabelecer os formatos do livro e dos requadros, para então testar diferentes modos de organizá-los nas páginas. Após a definição geral do layout (figuras 5 e 6), foram feitos os esboços iniciais das cenas de cada requadro de acordo com o roteiro, com um total de 56 páginas. Toda a criação se deu por meio do software de desenho à mão livre Paint Tool Sai. 
Figura 1: Layout das páginas.

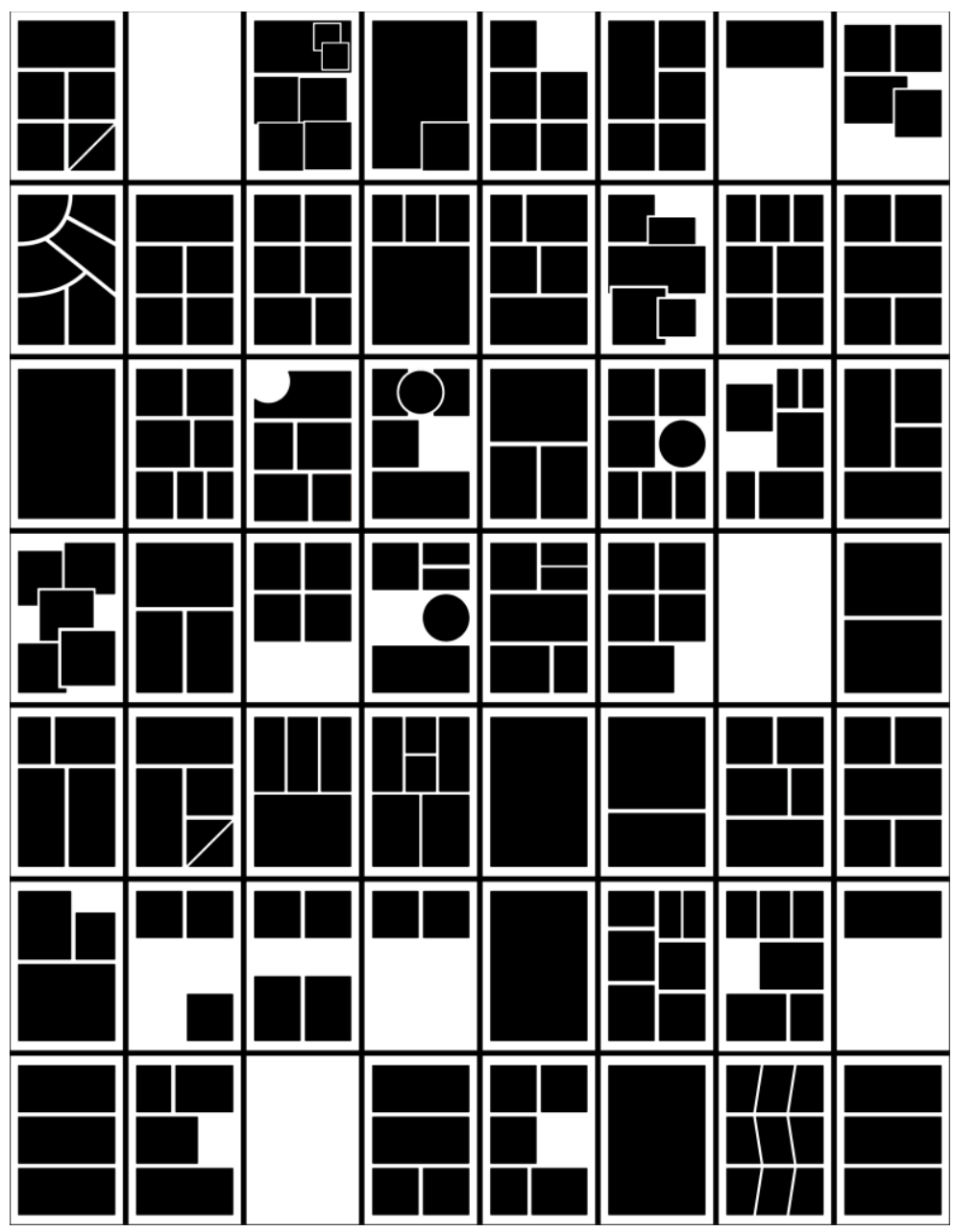

Figura 6: Storyboard desenhado a mão (lápis sobre papel offset $75 \mathrm{~g}$ ) e montado em modelo físico para teste de cadernos.

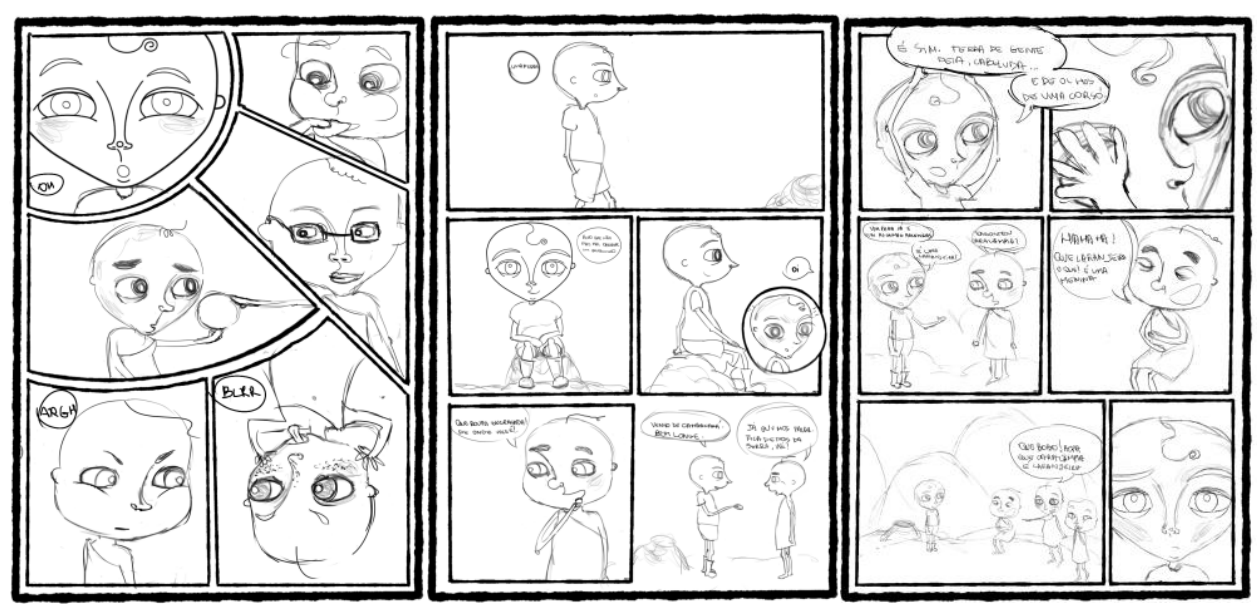

\section{Definição e refinamento da solução final}

Nesta etapa ocorreu a realização do processo de composição e aperfeiçoamento da proposta para a solução final do produto da fase 01 , bem como a produção da arte de capa (figura 7 ), a partir da aplicação de cor através do software Paint Tool Sai. Além da arte de capa, foram definidas ilustrações para compor as contracapas ou páginas de guarda (figura 8). 


\section{\begin{tabular}{ll|l|l} 
CIDI 2017 & $\begin{array}{l}8^{\text {th }} \\
\text { CIDI }\end{array}$ & $8^{\text {th }}$ CONGIC & $\begin{array}{l}\text { Blucher Design Proceedings } \\
\text { Junformation Design }\end{array}$ \\
$8^{\text {th }}$ Information Design & Junho 2018, num. 1, vol. 4
\end{tabular}}

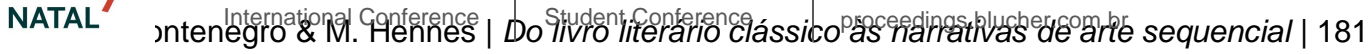

Figura 7: Capa e contracapa.

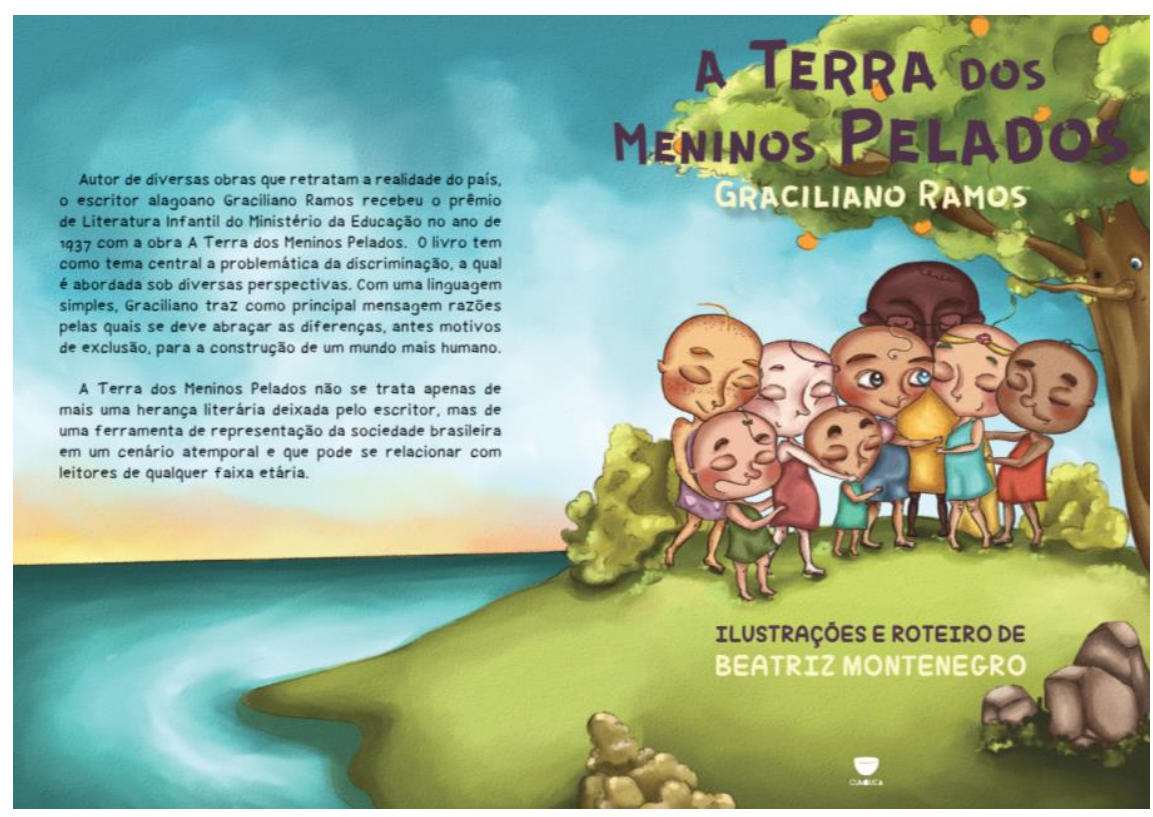

Figura 8: Páginas de guarda.

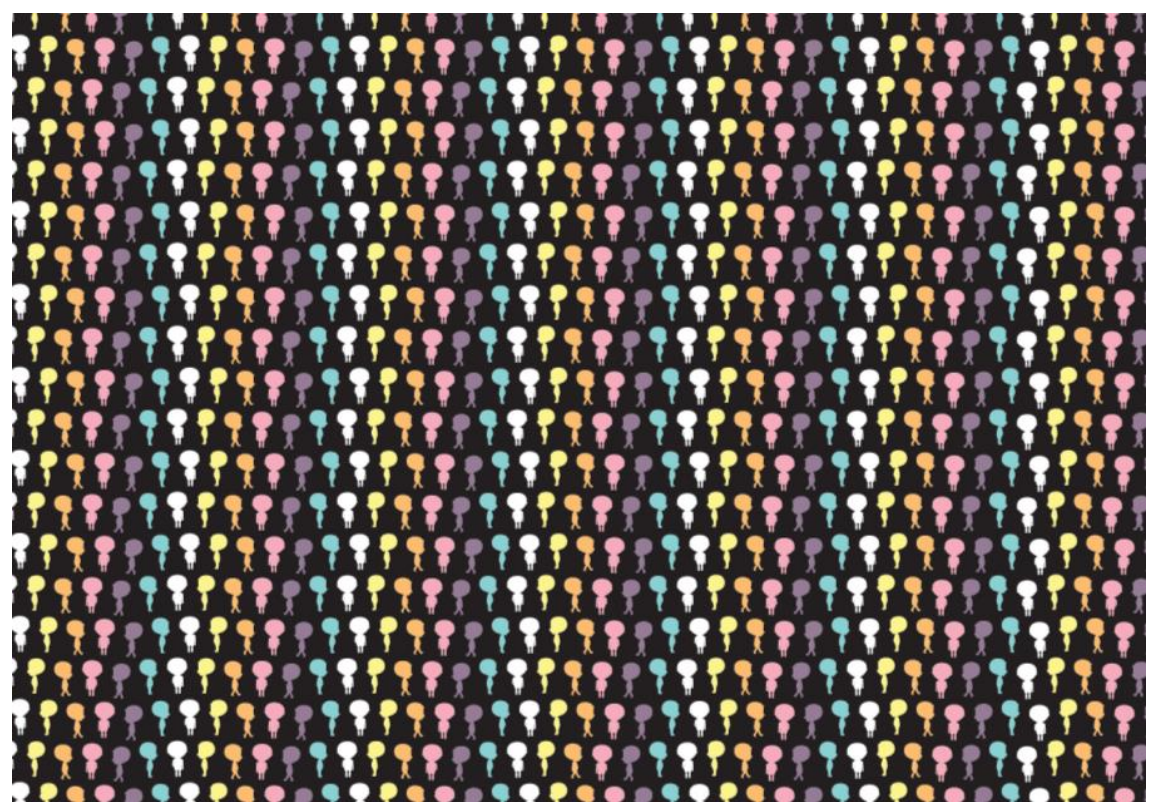

\section{Projeto Editorial}

Análise de similares

Nesta etapa de desenvolvimento editorial do projeto, foi feita uma breve análise gráfica dos projetos editoriais similares Laços (da turma da Mônica), Pétalas e The Little Prince. Nessa etapa, aspectos como materiais e processos utilizados na capa, encadernação e miolo foram identificados e descritos, bem como a existência de acabamentos especiais. Tal análise nos deu permitiu refletir sobre quais alternativas seriam mais adequadas à aplicação na presente proposta, considerando as características positivas e negativas de cada item. 


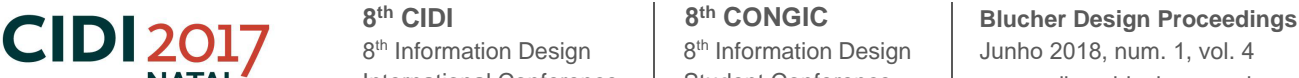

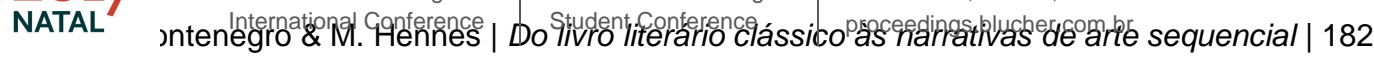

\section{Geração de alternativas}

Com os resultados obtidos na primeira fase da metodologia, foram selecionados os materiais e processos gráficos que melhor se adequariam ao projeto. Foi montada, então, uma tabela levando em consideração os materiais mais recorrentes nas graphic novels analisadas.

Tabela 2: Geração de alternativas.

\begin{tabular}{l|l|l|l|l} 
Alternativa & Capa & Encadernação & Miolo & Acabamentos \\
\hline 1 & Dura & Com costura & $\begin{array}{l}\text { Couché } \\
90 \mathrm{~g} / \mathrm{m}^{2}\end{array}$ & $\begin{array}{l}\text { Laminação } \\
\text { brilhosa (capa e } \\
\text { miolo)/impressão } \\
\text { de jaqueta }\end{array}$ \\
\hline 2 & Triplex $250 \mathrm{~g} / \mathrm{m}^{2}$ & Brochura & $\begin{array}{l}\text { Couché } \\
120 \mathrm{~g} / \mathrm{m}^{2}\end{array}$ & $\begin{array}{l}\text { Laminação fosca } \\
\text { (capa e } \\
\text { miolo)/verniz U.V. } \\
\text { localizado/colagem }\end{array}$ \\
\hline
\end{tabular}

\section{Escolha da alternativa}

A partir das especificações de material e acabamentos gerados na etapa anterior, foi feito um levantamento de custo de produção, iniciando-se na solicitação do orçamento das alternativas 01 e 02 para tiragens de 5 e 10 cópias. Embora a tiragem seja pequena, foi possível observar diferenças de valores entre as duas opções de produção gráfica, com indicativos de qual opção teria menor custo, caso o livro fosse impresso em grande tiragem.

Por conta da quantidade de folhas total (30) e pela intenção de garantir ao produto final um valor mais acessível, atingindo, assim, um maior número de leitores, foi escolhida a solução de impressão para capa flexível em papel triplex $250 \mathrm{~g} / \mathrm{m}^{2}$, com encadernação brochura, e miolo em papel offset $120 \mathrm{~g} / \mathrm{m}^{2}$. Optou-se pela laminação fosca tanto para a capa quanto para o miolo e aplicação de verniz U.V. localizado para o título da graphic novel, na capa. Além disso, em duas páginas foi incluído um acabamento especial, com colagens de tecido cetim azul para representar a túnica utilizada pelo protagonista em algumas cenas.

\section{Diagramação}

Feita simultaneamente ao desenvolvimento do storyboard, nesta etapa foram determinados os estilos e tamanhos dos requadros, os estilos e formatos dos balões e as fontes tipográficas utilizadas nos balões de texto comuns e em outras situações, como nos requadros com ilustração especial e em falas mais expressivas.

Foi estabelecido um tamanho padrão quadrado, com os cantos arredondados, a partir do qual surgiram outros, maiores e menores, retangulares, circulares ou sem formato específico, de acordo com a necessidade do roteiro, conforme mostra a figura 9.

Figura 9: Estilos de requadros.
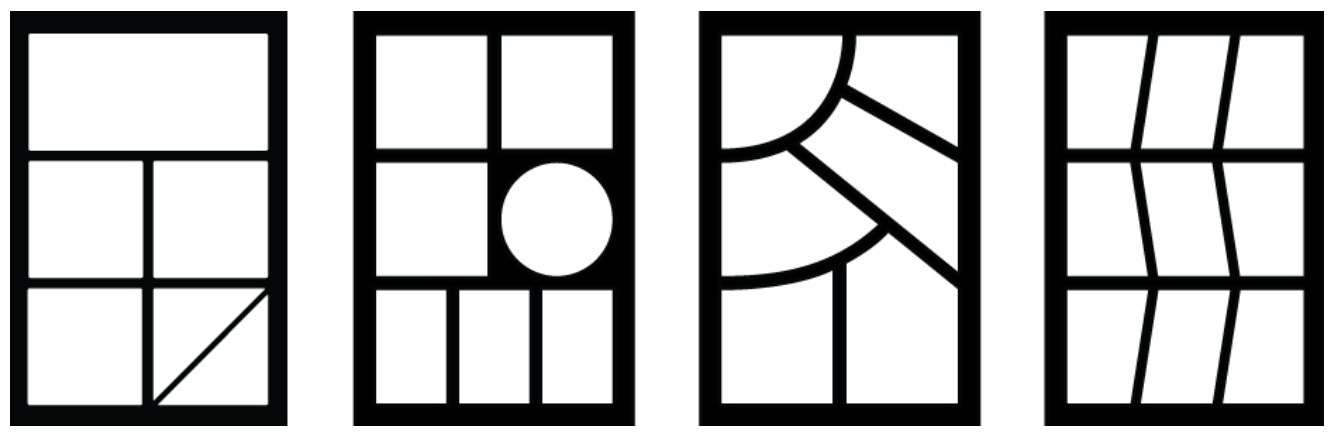

Para os balões (figura 10), foram definidos dois estilos: um para as falas e outro para os pensamentos. Com o intuito de diferenciá-los da cor do papel branco, o balão de fala recebeu uma cor levemente amarelada, enquanto o balão de pensamentos teve formato de nuvem e recebeu preenchimento preto. Em algumas páginas, todos os balões de fala sob fundo branco foram coloridos de rosa e azul, para melhor visualização. 
Figura 10: Balões.

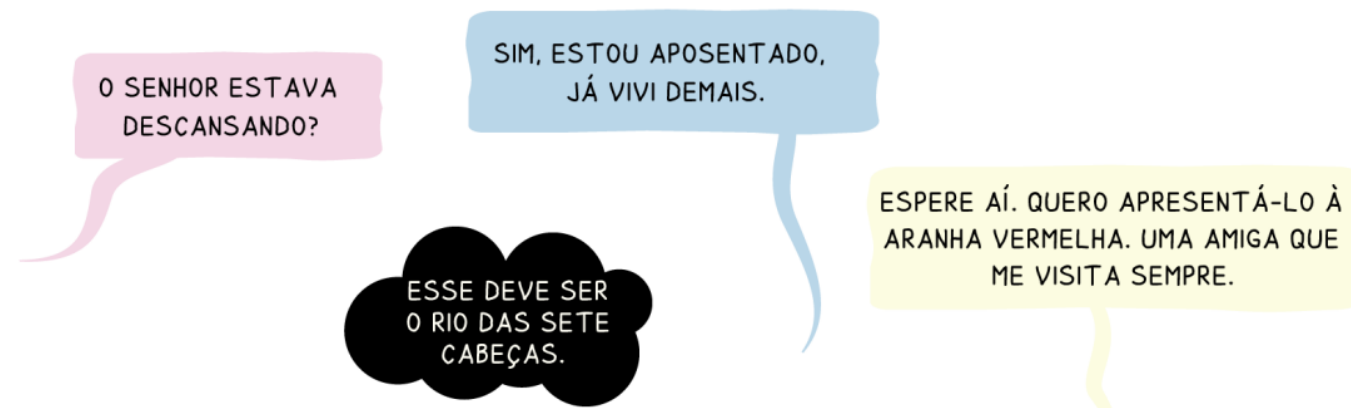

Sobre o estilo tipográfico, inicialmente, foi feita uma seleção de cinco fontes diferentes (figura 11), aplicadas em uma mesma página, as quais foram mostradas a dez crianças entre 8-12 anos, de escolas e classes sociais variadas. Houve certa dificuldade no momento da escolha pela fonte com maior legibilidade e adequação ao tema, já que a maioria das crianças não conseguiu visualizar a diferença entre as fontes tipográficas apresentadas.

Figura 11: Seleção de fontes tipográficas.

SIM. TERRA DE GENTE FEIA,

CABELUDA, COM OS OLHOS DE UMA COR SÓ. VIM PARA CÁ E TIVE ALGUMAS AVENTURAS.

COYOTRIS COMIC
SIM. TERRA DE GENTE FEIA.

CABELUDA, COM OS OLHOS DE UMA COR SÓ. VIM PARA CÁ E TIVE ALGUMAS AVENTURAS.

HOOTEROL
SIM TERRA DE GENTE FEIA CABELUIDA COM OS OLHOS DE UMA COR SÓ. VIM PARA CÁ E TIVE ALGUMAS AVENTURAS

KOMIKA HAND
SIM. TERRA DE GENTE FEIA, CABELUDA, COM OS OLHOS DE UMA COR SÓ. VIM PARA CÁ E TIVE ALGUMAS AVENTURAS.

CHUNKSTER JAMZ
SIM. TERRA DE GENTE FEIA, CABELUDA, COM OS OLHOS DE UMA COR SÓ. VIM PARA CÁE TIVE ALGUMAS AVENTURAS.

VENTURA EDDING

Ainda assim, quatro escolheram a fonte Coyotris Comic, quatro escolheram a fonte Hooterol e duas crianças optaram pela fonte Komika Hand. Após os resultados, as três páginas contendo as fontes mais votadas foram apresentadas a dez adultos entre 20-35 anos, de profissões e classes sociais inespecíficas. Mais uma vez, a maioria dos participantes não conseguiu visualizar com facilidade a diferença entre as fontes. Cinco escolheram a fonte Coyotris Comic, quatro escolheram a fonte Hooterol e apenas um optou pela fonte Komika Hand. Ao final, somou mais pontos a fonte Coyotris Comic, com 9 votos, em segundo lugar a fonte Hooterol, com 8 votos e em terceiro lugar a fonte Komika Hand, com 3 votos. Pela votação, foi escolhida a fonte Coyotris Comic como fonte principal e a fonte Gagalin (figura 12) como fonte secundária, utilizada em falas que exprimem maior volume ou tom dramático.

Figura 12: Fonte Gagalin.

\section{QUE INFELICIDADEI}

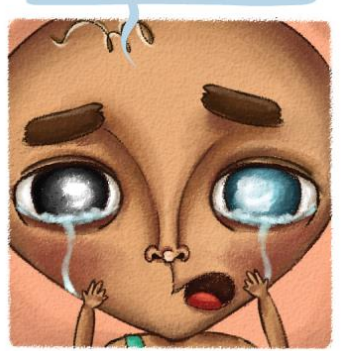




\section{CIDI 2017

Ao final da etapa de diagramação, construiu-se um infográfico (figura 13) que reuniu os principais dados referentes aos elementos verbais, pictóricos e produção gráfica do projeto de adaptação da obra $A$ Terra dos Meninos Pelados para narrativa em arte sequencial.

Figura13: Infográfico com panorama geral do projeto gráfico da obra A Terra dos meninos Pelados em formato de graphic novel.

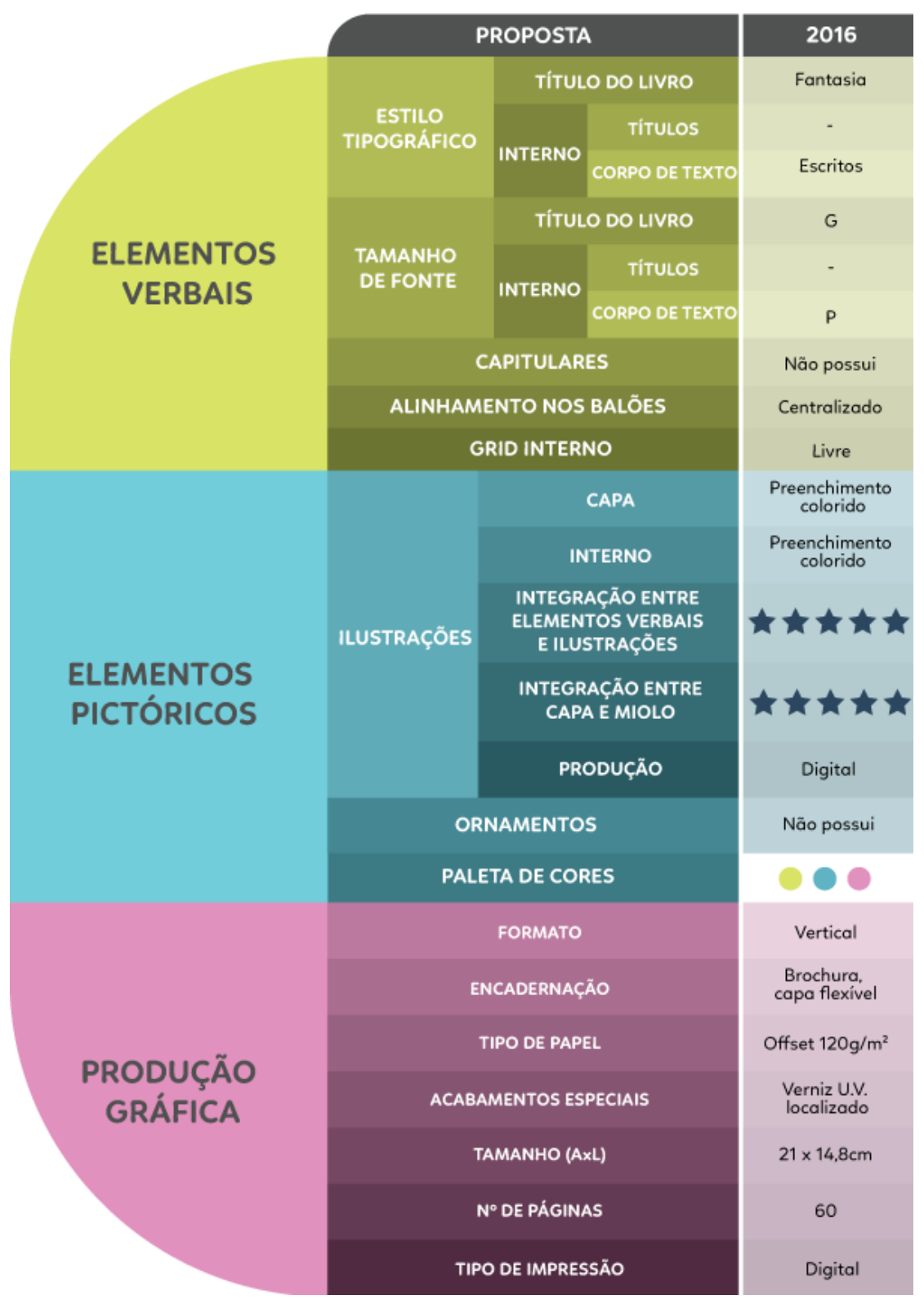

\section{Detalhamento técnico}

Para a impressão do livro, o detalhamento seguiu as especificações: papel triplex $250 \mathrm{~g} / \mathrm{m}^{2}, 4 \times 4$ cores para capa, com acabamento em refile trilateral, encadernação brochura, laminação fosca e verniz localizado. Já para o miolo, foi utilizado papel offset $120 \mathrm{~g} / \mathrm{m}^{2}, 4 \times 4$ cores, com acabamento em refile trilateral, vinco central, encadernação brochura e laminação fosca. Devido ao número baixo da tiragem (10 unidades), o mockup da graphic novel foi impresso em processo digital.

\section{Produção de mockup}

Nesta fase foram produzidos mockups digitais do projeto (figura 14) como simulações dos mockups impressos do livro. 
Figura 14: Mockup digital da graphic novel A Terra dos Meninos Pelados.

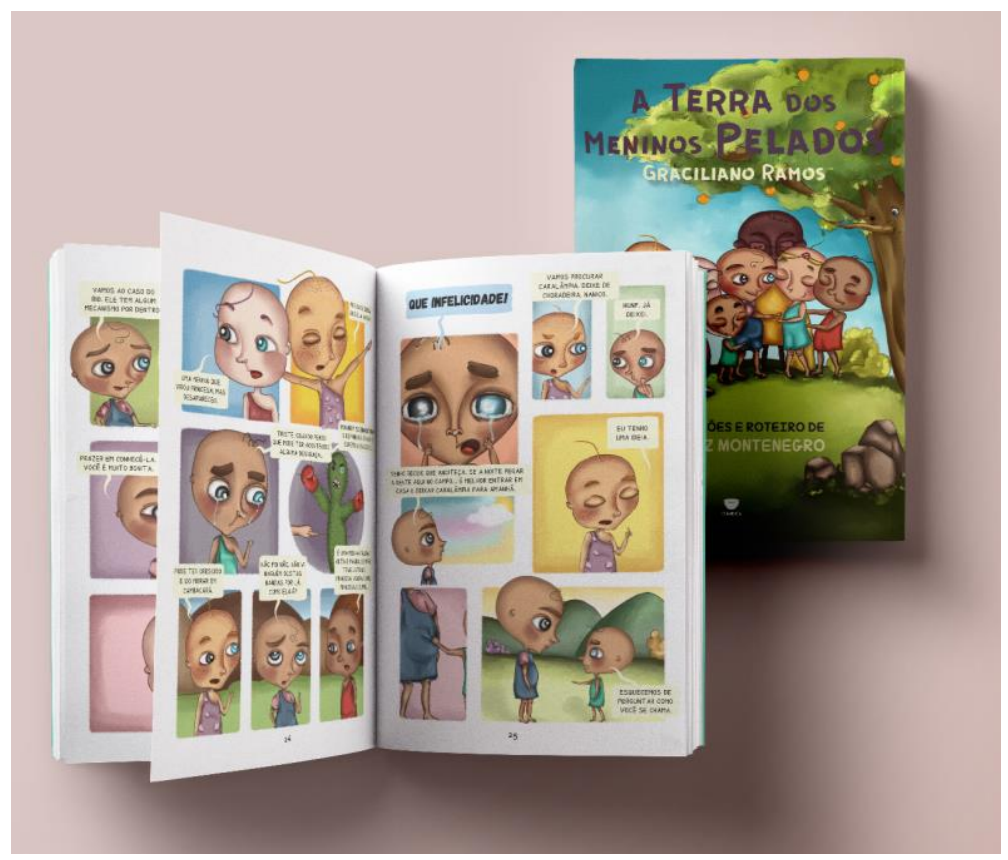

\section{Considerações finais}

A obra A Terra dos Meninos Pelados, clássico da literatura infantil nacional, caracteriza-se como uma das principais heranças literárias deixadas por Graciliano Ramos, um dos maiores escritores brasileiros, não apenas pela originalidade do romance, mas também pela contemporaneidade observada na temática principal do livro: o preconceito.

A fim de aproximar o público leitor infanto-juvenil da realidade vivida pelo protagonista na história, foi proposta uma releitura do conto, adotando-se uma abordagem contemporânea, por meio da narrativa em arte sequencial no formato de graphic novel. Assim, fez-se um estudo comparativo de duas metodologias (Selbach, 2010; Festenseifer, 2012) utilizadas no desenvolvimento de trabalhos similares. Algumas de suas etapas foram adaptadas de modo a gerar uma metodologia que melhor se adequasse aos processos ilustrativo e editorial referentes ao projeto tratado neste artigo.

O desenvolvimento do projeto gráfico editorial da graphic novel se deu a partir da análise dos aspectos culturais e sociológicos presentes na obra, a fim de identificar as características físicas e psicológicas das personagens. Posteriormente, iniciou-se a fase de criação do concept art, adotado na etapa de ilustrações, e dos aspectos gráficos e compositivos dos layouts, na qual se utilizou como diretriz, o mapeamento de materiais e processos gráficos existentes no mercado, passíveis de serem aplicados a um custo condizente com esse tipo de artefato.

Diante disso, chegou-se a produção de um trabalho que garantiu não somente a presença de elementos e recursos gráficos eficientes, mas fundamentalmente que se adequaram ao público-alvo, tanto no que diz respeito à adaptação textual do roteiro quanto nas escolhas dos estilos gráficos e materiais de produção gráfica que pudessem despertar, sobretudo, na criança e no jovem, o interesse pela leitura.

\section{Referências}

AMBROSE, G.; HARRIS, P. 2009. Impressão \& acabamento. Porto Alegre: Bookman.

FARBIARZ, A.; FARBIARZ, J. 2010. O entrelugar do design na interação entre o livro e o leitor.

Design: olhares sobre o livro. Organização: Luiz Antônio Coelho, Alexandre Farbiarz.

Teresópolis: Editora Novas Ideias. 
FENSTERSEIFER, T. 2012. Design Editorial: os livros infantis e a construção de um público leitor. Dissertação (trabalho de conclusão de curso). Universidade Federal do Rio Grande do Sul, Porto Alegre.

FONSECA, J. 2008. Tipografia \& Design Gráfico: design e produção gráfica de impressos e livros. Porto Alegre: Bookman.

LINS, G. 2003. Livro Infantil: projeto gráfico, metodologia, subjetividade. São Paulo: Edições Rosari.

MCCLOUD, S. 1995. Reinventando os Quadrinhos. São Paulo: Ed. M. Books.

PLATTHAUS, A. 2011. "Graphic novel": algo mais do que história em quadrinhos. Em $<$ http://www.dw.com/pt/graphic-novel-algo-mais-do-que-historia-em-quadrinhos/a15364273>, 12/06/2016.

PEÓN, M. L.2000. Sistemas de Identidade Visual. Rio de Janeiro: 2AB.

SELBACH, L. 2010. A Cor que veio do espaço: Uma adaptação literária para Histórias em Quadrinhos. Trabalho de conclusão de curso não publicado. Universidade Federal do Rio Grande do Sul, Porto Alegre.

Romani, E. 2011. Design do livro-objeto infantil. Dissertação de Mestrado, Faculdade de Arquitetura e Urbanismo, Universidade de São Paulo, São Paulo. <http://www.teses.usp.br/teses/disponiveis/16/16134/tde-11012012-115004/pt-br.php>, 09/06/2017.

YAMAGUTI, V. 2014.As adaptações literárias em quadrinhos selecionadas pelo PNBE: soluções e problemas na sala de aula. In:Olh@res, v.2, n.1, p.441-459.

\section{Sobre o(a/s) autor(a/es)}

Beatriz Montenegro, BSc, UFAL, Brazil <biafcm@gmail.com>

Mariana Hennes, MSc, UFAL, Brazil <mhennes.design@gmail.com> 